\title{
Caffeine induces sustained apoptosis of human gastric cancer cells by activating the caspase-9/caspase-3 signalling pathway
}

\author{
HANYANG LIU, YAN ZHOU and LIMING TANG \\ Department of Gastrointestinal Surgery, Nanjing Medical University, Affiliated Changzhou No. 2 People's Hospital, \\ Changzhou, Jiangsu 213000, P.R. China
}

Received April 6, 2016; Accepted April 25, 2017

DOI: $10.3892 / \mathrm{mmr} .2017 .6894$

\begin{abstract}
Caffeine is one of the most widely consumed substances found in beverages, and has demonstrated anticancer effects in several types of cancer. The present study aimed to examine the anticancer effects of caffeine on gastric cancer (GC) cells (MGC-803 and SGC-7901) in vitro, and to determine whether the apoptosis-related caspase-9/-3 pathway is associated with these effects. The sustained antiproliferative effects of caffeine on gastric cancer were also investigated. GC cell viability and proliferation were evaluated using cell counting and colony forming assays, following treatment with various concentrations of caffeine. Flow cytometry was performed to assess cell cycle dynamics and apoptosis. Western blot analysis was conducted to detect the activity of the caspase-9/-3 pathway. The results indicated that caffeine treatment significantly suppressed GC cell growth and viability and induced apoptosis by activating the caspase-9/-3 pathway. Furthermore, the anticancer effects of caffeine appeared to be sustained, as the caspase-9/-3 pathway remained active following caffeine withdrawal. In conclusion, caffeine may function as a sustained anticancer agent by activating the caspase-9/-3 pathway, which indicates that it may be useful as a therapeutic candidate in gastric cancer.
\end{abstract}

\section{Introduction}

Gastric cancer (GC) is a highly lethal malignancy that ranks amongst the top ten most frequent cancers, and is a leading cause of cancer-related mortality. In Asian countries, including China, Japan and Korea, gastric cancer accounts for approximately $60 \%$ of new cancer cases (1). GC is a complex and molecularly heterogeneous disease, which is associated

Correspondence to: Professor Liming Tang, Department of Gastrointestinal Surgery, Nanjing Medical University, Affiliated Changzhou No. 2 People's Hospital, 68 Gehu Road, Changzhou, Jiangsu 213000, P.R. China

E-mail: halfmoonstar@foxmail.com

Key words: caffeine, stomach neoplasms, sustained medication, apoptosis, caspases with lifestyle, age-related, environmental and genetic factors. Smoking, alcohol use and improper food intake are leading risk factors for GC morbidity and mortality worldwide (2). Obesity and being overweight and are also important causes of GC, especially in high-income countries (3) Furthermore, $H$. pylori infection is an established environmental risk factor for GC (4). Several canonical oncogenic signalling pathways, including the tumor protein $\mathrm{p} 53$, wnt/ $\beta$-catenin, nuclear factor (NF)- $\mathrm{B}$ and phosphatidylinositol-3-kinase (PI3K)/Akt pathways, are associated with gastric carcinogenesis (5). Caspases are cysteine-dependent, aspartate-specific proteases associated with apoptosis, a process that is regulated by several oncogenic pathways. Caspase- 9 is a key effector caspase in the intrinsic apoptosis pathway. Release of cytochrome $c(\mathrm{Cyt}-c)$, a protein found in the mitochondrial inner membrane, activates procaspase-9 to caspase-9, which in turn converts procaspase-3 to cleaved caspase- 3 . These closely linked events lead to cell apoptosis; thus, caspase- 9 is considered a therapeutic target in cancer treatment (6).

Caffeine is a methylxanthine derivative found in coffee, cacao and tea, and is the most widely consumed psychoactive substance in the world. Caffeine intake induces several normal physiologic effects, including nervous and musculoskeletal system stimulation, bronchial and vascular smooth muscle relaxation, diuresis and intestinal motility stimulation (7-12). Caffeine also exerts various pharmacological effects. Several epidemiological and experimental studies have reported that caffeine may have potential as an anticancer agent due to its ability to suppress cell proliferation and induce apoptosis in multiple organs, including the oesophagus, breast, liver and brain, via several oncogenic pathways, including phosphatase and tensin homolog (PTEN), PI3K/Akt, p53 and mammalian target of rapamycin (mTOR) pathways (13-21). However, the caspases have received limited attention. A few studies have demonstrated that caspase- 9 and -3 may serve important roles in caffeine-induced cancer cell apoptosis $(22,23)$; however, the molecular signalling pathways associated with these processes remain to be elucidated. Furthermore, previous research has indicated that caffeine may have sustained effects following withdrawal (20), the underlying mechanism of which remains unknown.

In the present study, two gastric cell lines were selected for examining the anticancer effect of caffeine on gastric cancer; MGC-803 is classified as a poorly differentiated 
gastric cancer cell line and SGC-7901 is classified as a well differentiated gastric cancer cell line. Poorer cellular differentiation is associated with a higher degree of malignancy, therefore the present study aimed to investigate the anticancer effects of caffeine on two types of malignant cancer cells. Furthermore, the effects of treatment with graded concentrations of caffeine were investigated on cell growth, apoptosis and the apoptosis-related proteins B cell lymphoma 2 (Bcl-2), Cyt- $c$, caspase- 9 and caspase-3. Finally, the post-withdrawal sustained effects of caffeine on cell viability, apoptosis and caspase-9/-3 signalling pathway activation were examined.

\section{Materials and methods}

Cell culture. The human gastric cancer cell lines MGC-803 (poorly differentiated gastric cancer cell line), SGC-7901 (well-differentiated gastric cancer cell line) and GES-1 (human gastric mucosa epithelial cells) were obtained from the Cell Resource Center of Shanghai Institute of Biochemistry and Cell Biology, Chinese Academy of Sciences (Shanghai, China). Cells were cultured in RPMI-1640 supplemented with $10 \%$ fetal bovine serum (both from Gibco; Thermo Fisher Scientific, Inc., Waltham, MA, USA). MGC-803 and SGC-7901 cells seeded at a density of $1 \times 10^{5}$ cells in a $100-\mathrm{mm}$ plate were used in the cell viability and colony formation assays, and for RNA and protein extraction. MGC-803 and SGC-7901 cells at a density of $3 \times 10^{4}$ cells/well in a 6 -well plate were used for flow cytometry. MGC-803 and SGC-7901 cells at a density of $5 \times 10^{3}$ cells/well in a 96-well plate were used in the Cell Counting Kit-8 (CCK-8) assay. GES-1 cells were seeded at a density of $2 \times 10^{5}$ cells/well in a $100-\mathrm{mm}$ plate and were used as untreated normal control cells. All cells were cultured at $37^{\circ} \mathrm{C}$ in a $5 \% \mathrm{CO}_{2}$ atmosphere.

Chemicals and experimental set-up. Caffeine (Sigma-Aldrich; Merck KGaA, Darmstadt, Germany) was dissolved in RPMI-1640 and then added to the culture medium. The cell growth inhibitor 5-fluorouracil (5-FU; Sigma-Aldrich; Merck $\mathrm{KGaA}$ ), which was used to evaluate the inhibitory effects of caffeine on cell proliferation, was dissolved in the culture medium. Cells treated with caffeine were considered the experimental group, cells treated with 5-FU were considered the control evaluation group and cells treated with equal amounts of RPMI-1640 plus 5\% fetal bovine serum were considered the normal control group. Two inhibitors, Z-LEHD-FMK (a specific inhibitor of caspase-9) and Z-DEVD-FMK (a specific inhibitor of caspase-3), were obtained from BioVision, Inc. (Milpitas, CA, USA).

Cell viability and colony-forming unit assays. Cell viability was analysed with CCK-8 reagent (CCK-8; Dojindo Molecular Technologies, Inc., Kumamoto, Japan). MGC-803 and SGC-7901 cells were cultured at a density of $3 \times 10^{4}$ cells/well in 96-well plates, and incubated at $37^{\circ} \mathrm{C}$ overnight. GC cells were subsequently treated with 4 different caffeine concentrations $(0,0.5,1$ or $2 \mathrm{mM})$ or $0.5 \mathrm{mg} / \mathrm{ml} \mathrm{5-FU}$ for $24 \mathrm{~h}$. CCK- 8 reagent $(10 \mu \mathrm{l})$ was added to each well, and the plates were incubated at $37^{\circ} \mathrm{C}$ for a further $3 \mathrm{~h}$. In the caffeine-withdrawal groups, GC cells were washed twice in PBS and cultured in caffeine-free serum for $24 \mathrm{~h}$ following caffeine treatment, and cell viability was evaluated via CCK-8 assay. The absorbance of the coloured formazan product, produced by mitochondrial dehydrogenases in metabolically active cells, was measured at $450 \mathrm{~nm}$ and the optical density of each well was recorded. A colony-forming unit assay was conducted to analyse cell clusters. Cells were cultured at a density of 100 cells/plate with caffeine (1 and $2 \mathrm{mM}$ ) for 2 weeks, and cells incubated in caffeine-free medium were established as the control group. Viable cells were subsequently stained with crystal violet and the results were photographed. Each experiment was performed $\geq 3$ times.

Flow cytometry analysis. MGC-803 and SGC-7901 cells were harvested following caffeine treatment. Double staining with fluorescein isothiocyanate (FITC)-Annexin V and propidium iodide (PI) was performed using an FITC-Annexin V Apoptosis Detection kit (BD Biosciences, Franklin Lakes, NJ, USA), according to the manufacturer's protocol. GC cells were analysed using a FACScan flow cytometer equipped with CellQuest Pro software version 5.1 (both from BD Biosciences). The cells were assessed as viable, dead, early apoptotic and late apoptotic, and the relative amounts of early apoptotic cells were compared with those of the control groups. Cells used for cell cycle analysis were stained with PI using a Cycletest ${ }^{\circledR}$ Plus DNA reagent kit (BD Biosciences), according to the manufacturer's protocol, and analysed using a FACScan flow cytometer. The percentages of cells in $\mathrm{G}_{0}-\mathrm{G}_{1}$, $\mathrm{S}$ and $\mathrm{G}_{2}-\mathrm{M}$ phase were counted and compared with those of the control groups.

Western blot analysis. Following treatment with various concentrations of caffeine, GC cells were lysed using radioimmunoprecipitation assay lysis buffer (Beyotime Institute of Biotechnology, Haimen, China) on ice for $40 \mathrm{~min}$ to extract the proteins. The protein concentration of the supernatants was determined via Bradford assay. Lysates ( $20 \mu \mathrm{g} /$ lane) were separated via $10 \%$ SDS-PAGE, transferred to $0.22 \mu \mathrm{m}$ polyvinylidene fluoride membranes (Sigma-Aldrich; Merck KGaA), and incubated at $4^{\circ} \mathrm{C}$ overnight with the following primary antibodies at a working dilution of 1:1,000, all purchased from Cell Signaling Technology, Inc. (Danvers, MA, USA): Anti-tubulin (cat no. 2148), anti-cyclin D1 (cat no. 2978), anti-cyclin dependent kinase (CDK)4 (cat no. 12790), anti-p21 (cat no. 2947), anti-Bcl-2 (cat no. 4223), anti-Bcl-2-associated death promoter (Bad; cat no. 9239), anti-Bcl-2-associated X protein (Bax; cat no. 5023), anti-Cyt-c (cat no. 11940), anti-caspase-9 (cat no. 9502), anti-cleaved caspase-9 (cat no. 20750), anti-caspase-3 (cat no. 9665), and anti-cleaved caspase-3 (cat no. 9664). Membranes were then incubated with mouse anti-rabbit secondary antibody (cat no. 3678; 1:1,000; Cell Signaling Technology, Inc.) at $4^{\circ} \mathrm{C}$ for $2.5 \mathrm{~h}$. Autoradiograms were semi-quantified via densitometry using ImageJ software version 1.46r (National Institutes of Health, Bethesda, MD, USA).

Reverse transcription-quantitative polymerase chain reaction $(R T-q P C R)$. Total RNA was extracted from the GC cell lines using TRIzol reagent (Invitrogen; Thermo Fisher Scientific, Inc.), according to the manufacturer's protocol. cDNA was synthesized with a PrimeScript ${ }^{\mathrm{TM}}$ RT reagent kit, and qPCR 
Table I. Primers used for quantitative polymerase chain reaction.

\begin{tabular}{lll}
\hline Gene & \multicolumn{1}{c}{ Forward primer $\left(5^{\prime}-3^{\prime}\right)$} & \multicolumn{1}{c}{ Reverse primer $\left(5^{\prime}-3^{\prime}\right)$} \\
\hline$\beta$-catenin & ATTGAAGCTGAGGGAGCCAC & TCCTGGCCATATCC ACCAGA \\
PTEN & ATGACAGCCATCATCAAAGAG & GACTTTTGTAATTGTGTATGCTGA \\
AKT & GTATGCTGGCAGAGTAGGAGAAC & CAGGTAACATCAGAGACAGACACA \\
mTOR & AGGCCGCATTGTCTCTATCAA & GCAGTAAATGCAGGTAGTCATCCA \\
P53 & ACGACGGTGACACGCTTCCCTG & CGCTAGGATCTGACTGCGGCTC \\
VEGF-A & CCCACTGAGGAGTCCAACAT & GATGATTCTGCCCTCCTCCTT \\
GAPDH & ATCATCCCTGCCTCTACTGG & GTCAGGTCCACCACTGACAC
\end{tabular}

PTEN, phosphatase and tensin homolog; mTOR, mammalian target of rapamycin; VEGF-A, vascular endothelial growth factor A; AKT, protein kinase B.

was performed with a SYBR ${ }^{\circledR}$ Premix Ex Taq ${ }^{\mathrm{TM}}$ kit (both from Takara Biotechnology Co., Ltd., Dalian, China) on a 7500 Real-Time PCR system (Applied Biosystems; Thermo Fisher Scientific, Inc.). Thermocycling conditions were as follows: Initial 1 step at $95^{\circ} \mathrm{C}$ for $10 \mathrm{~min}$, followed by 40 cycles at $95^{\circ} \mathrm{C}$ for $15 \mathrm{sec}$ and at $60^{\circ} \mathrm{C}$ for $1 \mathrm{~min}$. PCR primers (Sangon Biotech, Shanghai, China) for $\beta$-catenin, PTEN, AKT, mTOR, P53 and vascular endothelial growth factor A (VEGF-A) are listed in Table I. GAPDH served as an internal control, and fold changes were calculated using the $2^{-\Delta \Delta \mathrm{Cq}}$ method (24).

Statistical analysis. Data are expressed as the mean \pm standard error of the mean. The statistical significance of the differences between groups was assessed using one-way analysis of variance followed by a post hoc Student-Newman-Keuls test for multiple comparisons. Statistical analysis was performed using SPSS software version 16.0 (SPSS, Inc., Chicago, IL, USA). P $<0.05$ was considered to indicate a statistically significant difference. GraphPad Prism software version 6 (GraphPad Software, Inc., La Jolla, CA, USA) was used to calculate sensitivity and specificity.

\section{Results}

Caffeine inhibits GC cell growth and reduces viability in a concentration-dependent manner. MGC-803 and SGC-7901 cells were treated with caffeine at concentrations of $0.5,1,2$, 4 and $8 \mathrm{mM}$. Untreated GC cells served as controls, and the 5-FU-treated group was used to evaluate the effects of caffeine. Cell viability was measured by $\mathrm{CCK}-8$ assay. Cell viability was reduced by caffeine in both MGC-803 and SGC-7901 cells (Fig. 1A). The survival ratio significantly decreased to $<50 \%$ following $24 \mathrm{~h}$ caffeine treatment at concentrations of 4 and $8 \mathrm{mM}$. Caffeine treatment at high concentrations $(>2 \mathrm{mM})$ resulted in marked toxicity in normal gastric mucosa cells (data not shown), therefore, a concentration range of 0-2 mM was selected for subsequent experiments. To investigate the effects of caffeine on cell viability, GC cells were treated with $2 \mathrm{mM}$ caffeine and harvested at 12, 24, 36, 48, 60 and $72 \mathrm{~h}$, and cell viability was assessed via CCK-8 assay. The results indicated that the numbers of viable cells decreased as the concentration of caffeine increased (Fig. 1B and C). Furthermore, colony-forming unit assay indicated that colony forming efficiency was lower following caffeine treatment at concentrations of 1 and $2 \mathrm{mM}$ (Fig. 1D). These results indicate that caffeine treatment significantly inhibits MGC-803 and SGC-7901 cell viability and growth. Furthermore, this inhibitory effect may be concentration-dependent.

Caffeine inhibits cell cycle progression and promotes $G C$ cell apoptosis. To investigate whether caffeine is able to inhibit cell cycle progression and promote GC cell apoptosis, flow cytometry analysis was conducted. Caffeine treatment significantly inhibited cell cycle progression beyond the $G_{0} / G_{1}$ phase, furthermore, the $\%$ of cells in the $S$ phase was lower compared with the control group (Fig. 2A and B). There were no differences in the $\%$ of cells in each cell cycle phase amongst the caffeine-treated groups (Fig. 2A and B). Cell cycle-related protein expression was determined by western blot analysis. The results indicated that p21 levels were upregulated in MGC-803 cells and cyclin D1 levels were downregulated in both GC cell lines, following $2 \mathrm{mM}$ caffeine treatment (Fig. 2C). However, no differences in CDK4 protein expression were noted (Fig. 2C). Furthermore, apoptosis was promoted by caffeine treatment for $24 \mathrm{~h}$, which was particularly marked in SGC-7901 cells. Early apoptosis demonstrated the greatest increase, and this increase appeared to be concentration-dependent (Fig. 2D and E). 5-FU served as a positive control; flow cytometry indicated that the results for the 5-FU groups were similar to the results for the $2 \mathrm{mM}$ caffeine group. These results indicated that caffeine treatment results in cell cycle arrest and promotes MGC-803 and SGC-7901 cell apoptosis, providing supporting evidence for the potential cytotoxic effects of caffeine.

Caffeine induces GC cell apoptosis via the caspase-9/-3 pathway. The mechanism underlying the ability of caffeine to inhibit GC cell growth and induce apoptosis was investigated. It was hypothesised that apoptosis was driven by the caspase pathway in vitro. MGC-803 and SGC-7901 cells were treated with graded concentrations of caffeine for $24 \mathrm{~h}$ in the presence of serum. The expression of key apoptosis-related proteins (Bcl-2, Bad, Bax, Cyt- $c$, caspase-9 and caspase-3) was assessed by western blot analysis. Caffeine treatment increased the activation of caspase- 9 and -3 (cleaved caspase- 9 and -3 ), and increased the expression levels of Cyt- $c$ in 
A

\section{(2)}

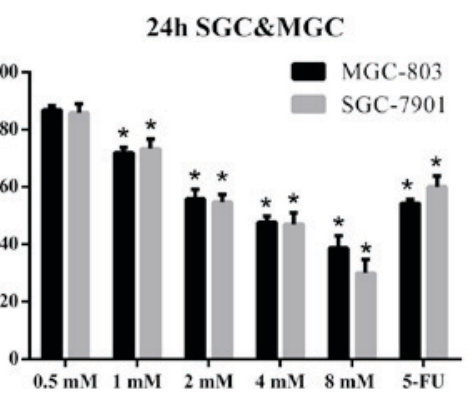

C

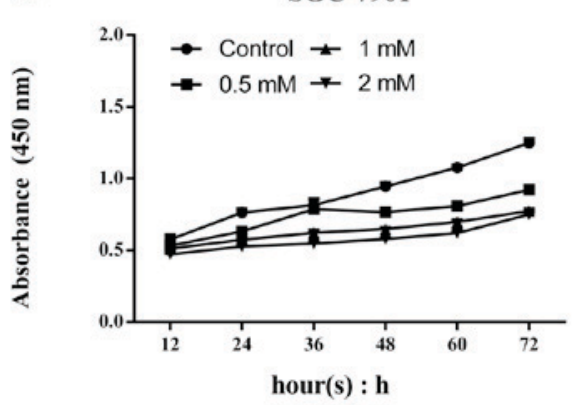

B

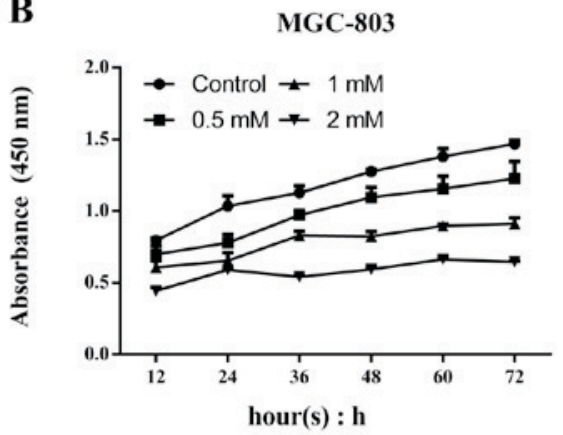

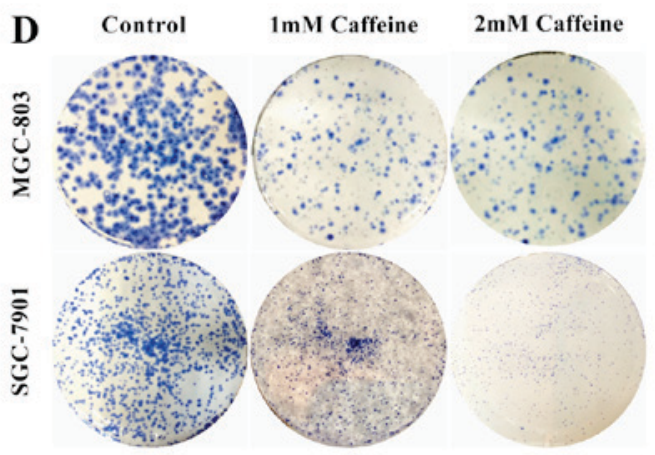

Figure 1. Caffeine inhibits GC cell growth in a concentration-dependent manner. GC cells were treated with the indicated caffeine concentrations and harvested at the indicated times. In addition, GC cells were treated with $5 \mathrm{mg} / \mathrm{ml} 5$-FU in the evaluation groups. Total cell survival was estimated by cell counts. (A) Relative cell viability was compared with that of the untreated control group. (B) MGC and (C) SGC cells were incubated with caffeine in 96-well plates and harvested at 12,24,36, 48, 60 and $72 \mathrm{~h}$. Cell Counting Kit- 8 reagent was added to each well at a dilution of $10 \mu \mathrm{l} / 100 \mu \mathrm{l}$, and the optical density at $450 \mathrm{~nm}$ was detected and recorded. (D) Cells were cultured with caffeine at a density of 100 cells/plate and were stained with crystal violet. Data are expressed as the mean \pm standard error of the mean of at least three independent experiments. ${ }^{*} \mathrm{P}<0.01$ vs. control. GC, gastric cancer; SGC, SGC-7901 cells; MGC, MGC-803 cells; OD, optical density; 5-FU, 5-fluorouracil.

MGC-803 and SGC-7901 cells, compared with the control group (Fig. 3A and B). Furthermore, Bcl-2 expression was reduced and Bax expression was increased with the indicated concentrations of caffeine, however, there were no significant differences in Bad expression (Fig. 3A and B). GC cells treated with caffeine at a concentration of $2 \mathrm{mM}$ exhibited the greatest differences in the expression of these proteins, compared with control cells and lower caffeine concentrations (Fig. 3A and B). These results indicate that caffeine treatment markedly influenced the expression of key proteins associated with apoptosis. Specific inhibitors of caspase-9 (5 $\mu \mathrm{M}$ Z-LEHD-FMK) and caspase-3 ( $5 \mu \mathrm{M}$ Z-DEVD-FMK) were used to investigate the association between the caspase-9/-3 pathway activation and the caffeine effect. The pro-apoptotic effects of caffeine were reversed by caspase- 9 and -3 inhibition (Fig. 3C). These data indicate that caffeine induces cell apoptosis via activation of the caspase-9/-3 pathway.

Caffeine exerts sustained effects on cell apoptosis after withdrawal. The effects of caffeine withdrawal were investigated to determine if the antiproliferative effects were sustained following drug withdrawal. GC-803 and SGC-7901 cells were incubated in caffeine-free medium for $24 \mathrm{~h}$ following caffeine treatment, and the post-withdrawal effects of caffeine on apoptosis-related pathways were investigated. GC cells were harvested at $0,8,16$ and $24 \mathrm{~h}$ following caffeine withdrawal, and their viability was assessed by CCK- 8 assay. The numbers of viable cells increased over time in all groups, however this was overall lower in the caffeine-treated groups compared with the 5-FU treated group (Fig. 4A). Notably, the number of viable cells was markedly reduced in the $2 \mathrm{mM}$ groups compared with the other groups (Fig. 4A). Based on these results, MGC-803 and SGC-7901 cells were harvested from the $2 \mathrm{mM}$ groups at $0,8,16$ and $24 \mathrm{~h}$ following caffeine withdrawal, and the levels of caspase- 9 and -3 were determined by western blot analysis. There were no significant differences in the levels of cleaved caspase- 9 and -3 in MGC-803 cells amongst these four time points, with the exception of the level of cleaved caspase-3 at $24 \mathrm{~h}$ (Fig. 4B and C). Similarly, there were no significant differences in the levels of cleaved caspase-9 in SGC-7901 cells between the four time points, with the exception of the levels of cleaved caspase- 9 at $24 \mathrm{~h}$. The levels of cleaved caspase-3 were decreased following caffeine withdrawal, with the greatest decrease in protein expression occurring at $24 \mathrm{~h}$ (Fig. 4B and D). These results suggest that the effects of caffeine on apoptosis and the corresponding increases in caspase-9/-3 levels are sustained following caffeine withdrawal.

The mRNA expression levels of several genes upstream of the caspases were measured via RT-qPCR, including $\beta$-catenin, PTEN, AKT, mTOR, p53 and VEGF-A. The results indicated that the relative mRNA expression levels of these genes were influenced by caffeine treatment. In MGC-803 and SGC-7901 cells, PTEN and p53 expression was upregulated and VEGF-A expression was downregulated following caffeine treatment for 24 h, compared with control (Fig. 5A). Furthermore, 
A
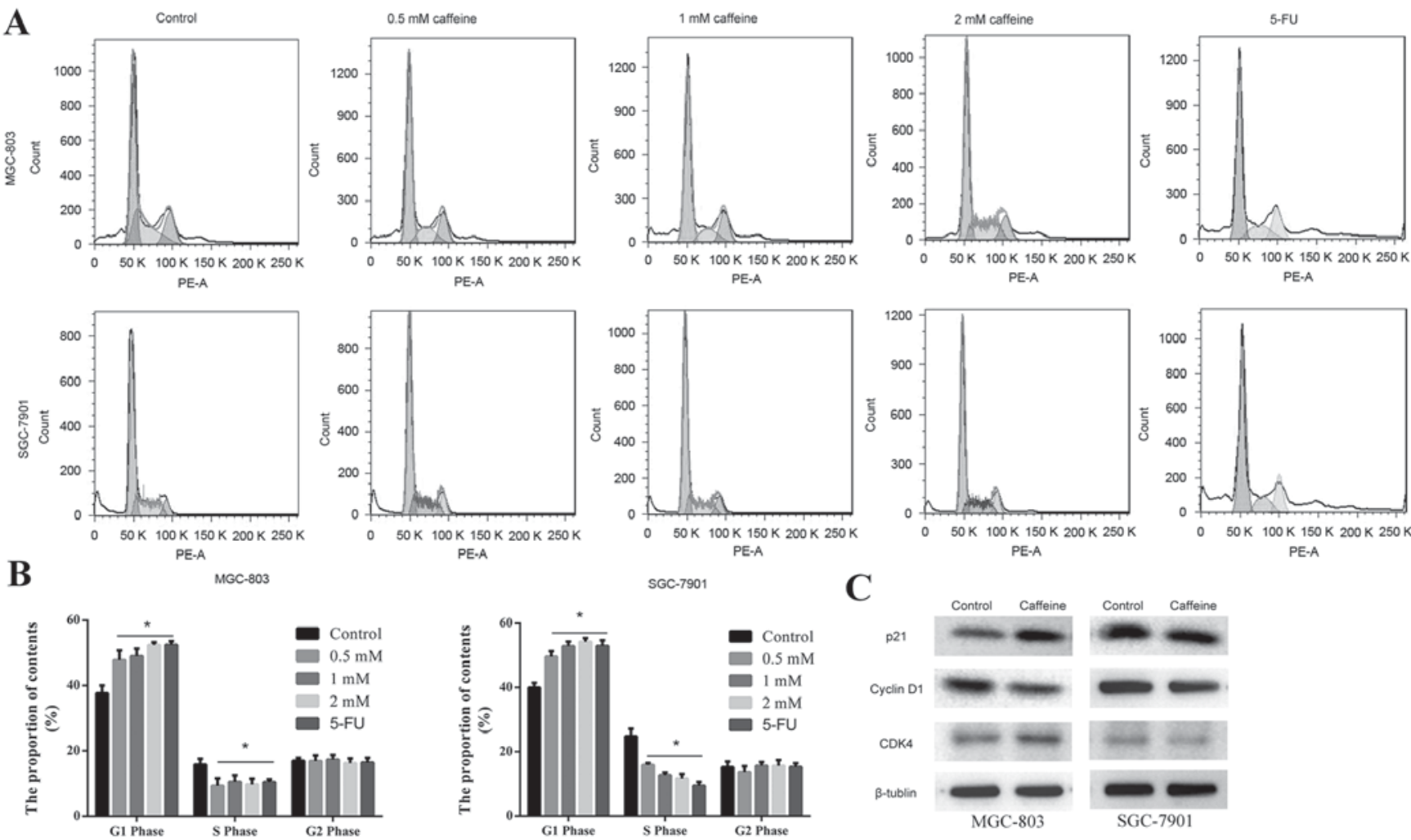

C
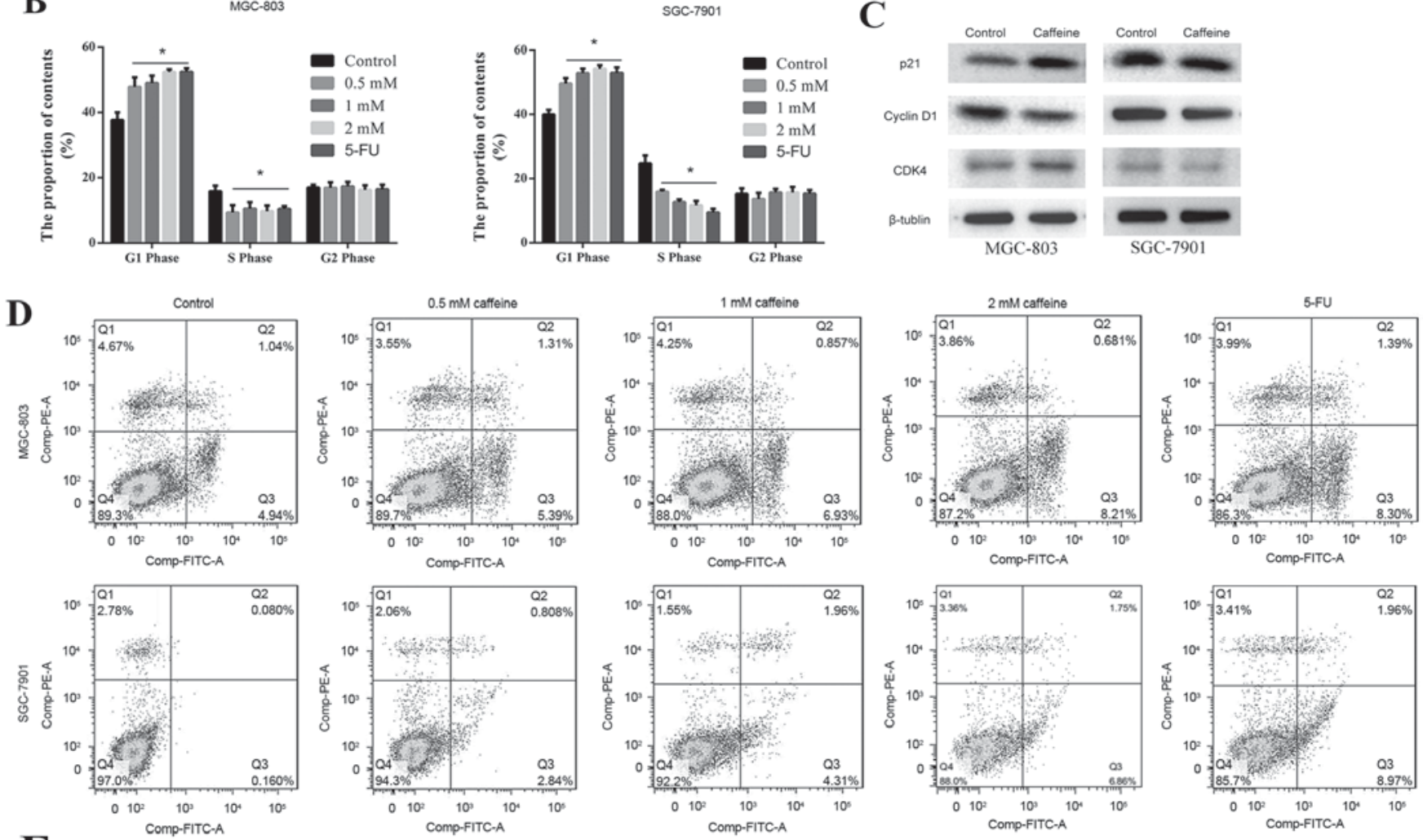

$\mathbf{E}$
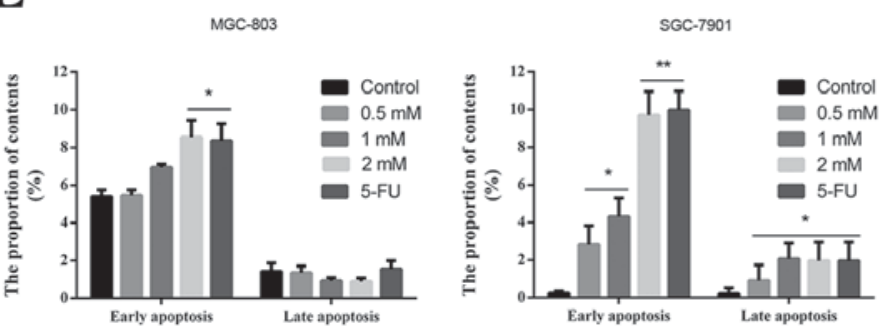

Figure 2. Caffeine induces cell cycle arrest and promotes GC cell apoptosis. Cells were obtained via enzymatic digestion following caffeine treatment for $24 \mathrm{~h}$ and then analysed via flow cytometry. (A and B) Representative plots and quantification of the cell cycle analysis performed by PI staining. (C) Protein levels of Cyclin D1, CDK4 and p21 were detected by western blot analysis. (D and E) Apoptosis was assessed via dual staining with PI and FITC-conjugated Annexin V. 5 -FU treatment served as a positive control. Data are expressed as the mean \pm standard error of the mean of at least three independent experiments. ${ }^{*} \mathrm{P}<0.05$ and ${ }^{* *} \mathrm{P}<0.01$ vs. control. GC, gastric cancer; PI, propidium iodide; FITC, fluorescein isothiocyanate; CDK4, cyclin dependent kinase 4; 5-FU, 5-fluorouracil; PE, phycoerythrin channel.

mTOR expression was downregulated in SGC-7901 cells (Fig. 5A). Relative mRNA expression quantification was also conducted in the caffeine-withdrawal groups. The relative expression levels of $\beta$-catenin, PTEN, AKT, mTOR, p53 and 


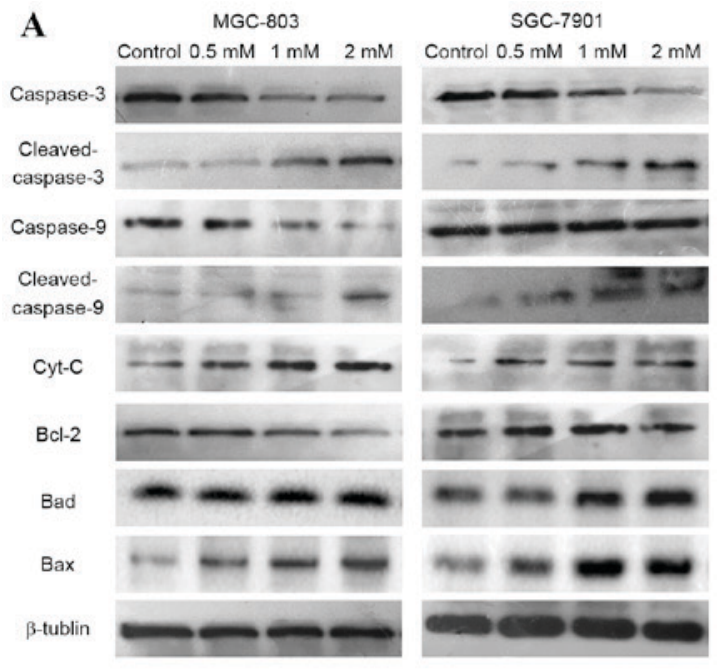

B
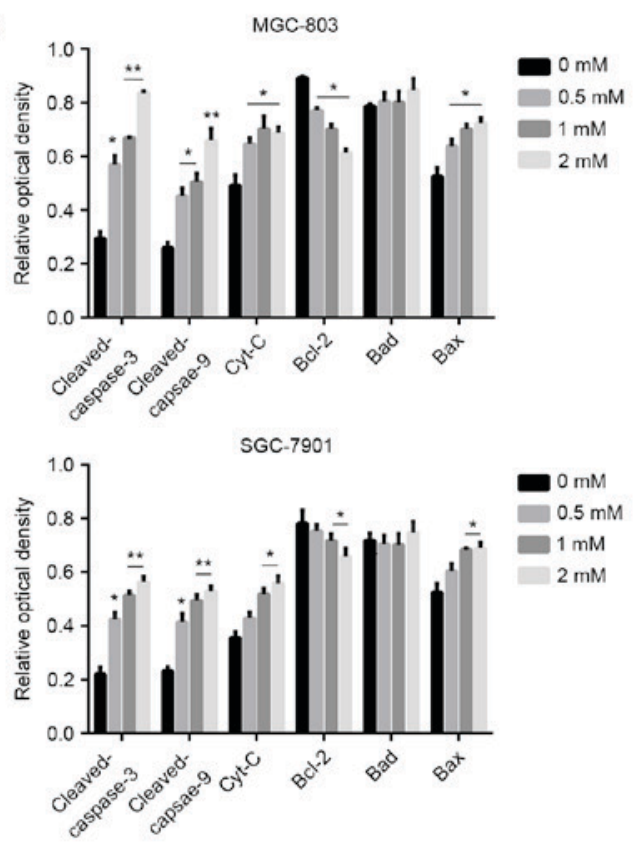

C

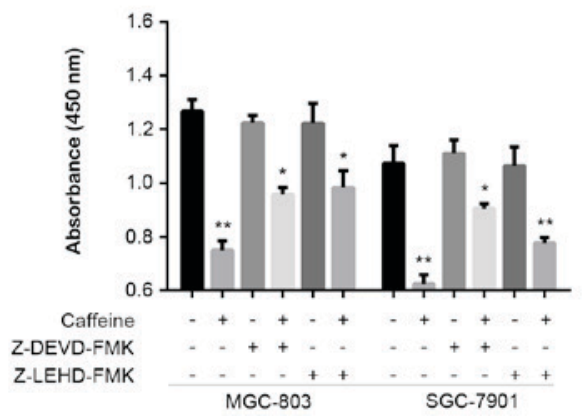

Figure 3. Caffeine induces GC cell apoptosis through the caspase-9/-3 pathway. GC cells were treated with the indicated caffeine concentrations and harvested at $24 \mathrm{~h}$. (A) Whole-cell lysates were assessed by immunoblotting analysis using antibodies against the indicated proteins. (B) Relative expression levels of the indicated proteins in GC cells are presented in histograms. Protein expression was semi-quantified by densitometry and normalized against $\beta$-tubulin. (C) Cells were incubated with caffeine and two caspase-specific inhibitors (Z-LEHD-FMK and Z-DEVD-FMK). The optical density at $450 \mathrm{~nm}$ was recorded and is shown in a histogram. Data are expressed as the mean \pm standard error of the mean of at least three independent experiments. ${ }^{*} \mathrm{P}<0.01$ and ${ }^{* *} \mathrm{P}<0.01$ vs. control. GC, gastric cancer; Cyt-c, cytochrome $c$; Bcl-2, B-cell lymphoma 2; Bax, Bcl-2-associated $\mathrm{X}$ protein; Bad, Bcl-2-associated death promoter; OD, optical density; Z-LEHD-FMK, caspase-9 inhibitor; Z-DEVD-FMK, caspase-3 inhibitor.
VEGF-A varied (against value ' 1 ' represening the endogenous control-normalized expression) over time. The results were compared across the treatment conditions; expression levels were observed to change with time following caffeine withdrawal. Only a few groups demonstrated stable expression levels (against value ' 1 ') with time. PTEN and p53 (in both cell lines) remained above value ' 1 ' prior to $16 \mathrm{~h}$, and mTOR (in SGC-7901) remained below value ' 1 ' prior to $8 \mathrm{~h}$ (Fig. 5B). These results suggest that caffeine treatment may influence the mRNA expression levels of several signalling molecules, which are vital components of cancer signalling pathways.

\section{Discussion}

The worldwide popularity of caffeine is attributable to its stimulatory effects on the nervous system, as it causes enhanced alertness, mental hyperactivity, arousal, wakefulness, enhanced cognitive abilities, enhanced pain tolerance and improvements in workplace efficiency. As the structure of caffeine is similar to that of adenosine, competitive binding of caffeine to adenosine receptors impacts upon the nervous system, which facilitates the release of various neurotransmitters at the synaptic cleft, including acetylcholine, norepinephrine, dopamine and others (25-28). In addition to these transient effects, several reports have emphasized that caffeine exerts many long-term beneficial effects, as it may protect against the development of age-related dementia and cognitive decline (29,30), as well as development of Alzheimer's disease and Parkinson's disease (31-34), suggesting that caffeine has neuro-protective effects. In addition, caffeine increases cAMP levels by inhibiting phosphodiesterase activity (35). Higher amounts of caffeine than are ordinarily possible are required by athletes to improve their physical performance and induce weight loss (36). Notably, an inverse association between coffee consumption and type 2 diabetes (T2DM) risk among Dutch individuals was first reported in 2002 (37). To date, numerous meta-analyses and prospective studies have demonstrated that regular coffee intake may reduce the risk of T2DM (38-42). These results demonstrate that coffee intake reduces T2DM risk via regulation of plasma glucose levels, insulin-glucose homeostasis, islet cell inflammation and pro-inflammatory mediators (43). It has also been reported that caffeine exerts anticancer effects resulting in suppression of carcinogenesis, proliferation, invasion and metastasis (44). Furthermore, several retrospective and prospective studies indicate that long-term caffeinated coffee intake reduces the morbidity and mortality associated with cancer $(45,46)$.

The present study demonstrated that caffeine treatment reduced cell growth and induced GC cell apoptosis (MGC-803 and SGC-7901) in vitro. MGC-803 cells are poorly differentiated GC cells, whereas SGC-7901 cells are well-differentiated GC cells. These cell lines were used to assess the putative anticancer effects of caffeine in cancer cells of various differentiation stages. The present findings indicated that caffeine effectively inhibited the proliferation and induced apoptosis in both cell lines. Caffeine has previously demonstrated antiproliferative effects in a concentration-dependent (particularly at high concentrations $\geq 1 \mathrm{mM}$ ) and time-dependent manner (47-50). In the present study, cell cycle arrest was induced by caffeine in a concentration- and time-independent 

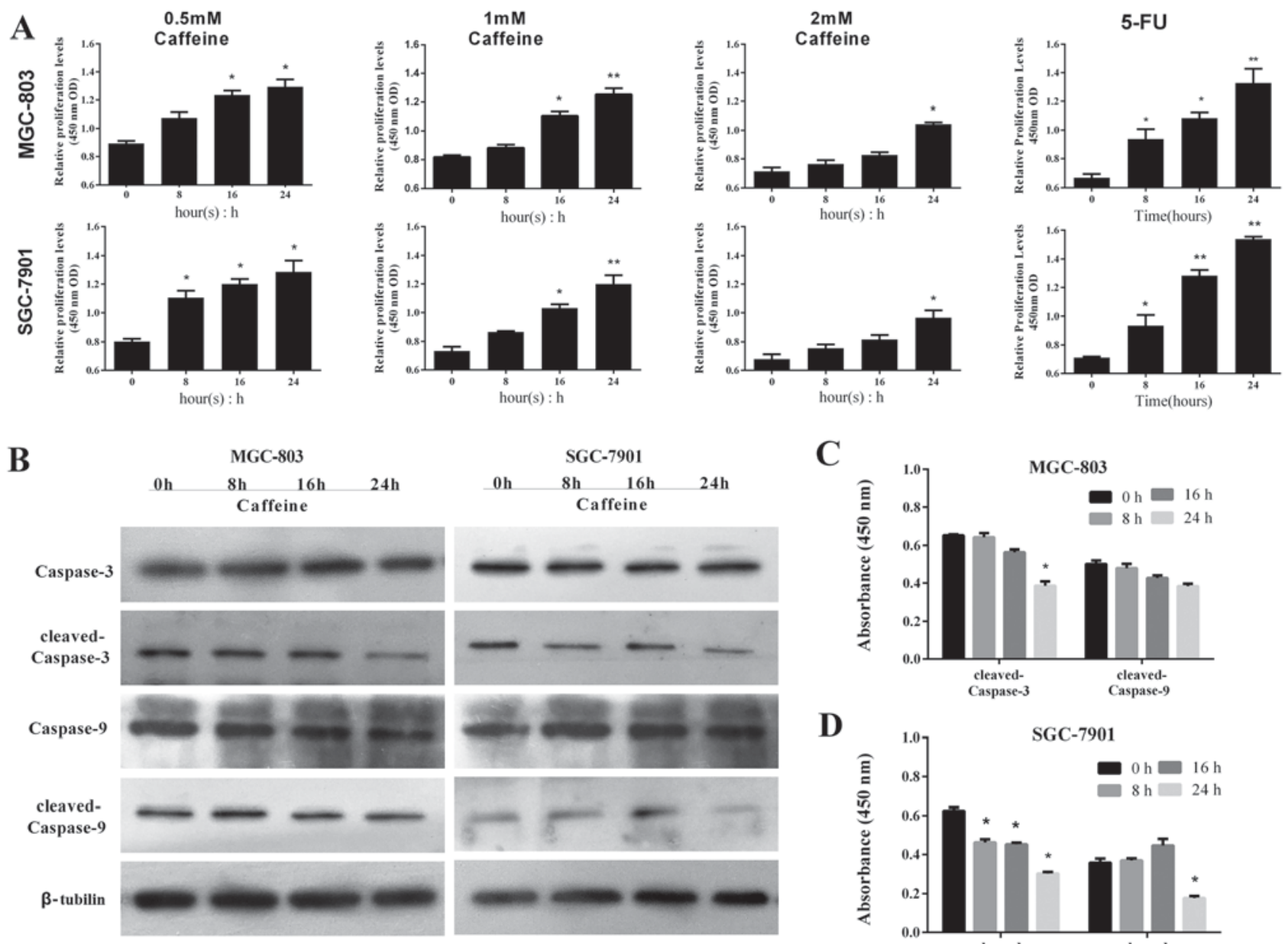

C

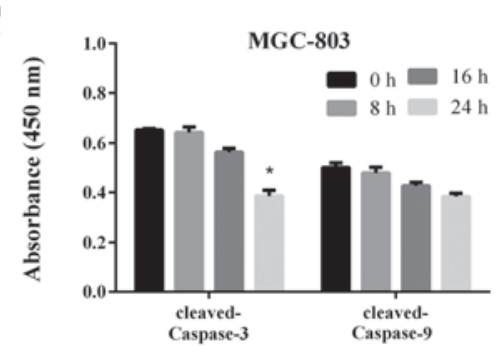

D

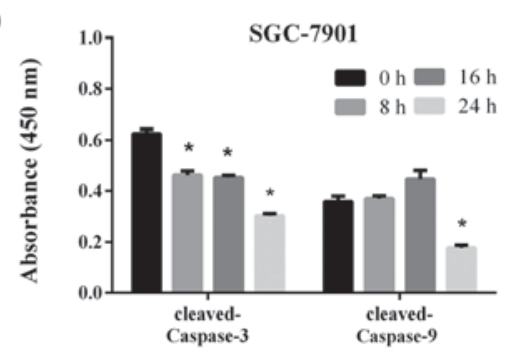

Figure 4. Caffeine treatment results in sustained activation of the caspase-9/-3 pathway and reduced cell viability. GC cells were treated with caffeine for $24 \mathrm{~h}$ and then incubated in caffeine-free culture media. Cells were harvested at $0,8,16$ and $24 \mathrm{~h}$. (A) The optical density detected at $450 \mathrm{~nm}$ is presented in histograms. (B) Whole-cell lysates were assessed via immunoblotting analysis using antibodies against the indicated proteins. (C and D) Expression levels of the indicated proteins in GC cells are presented in histograms. Expression values were measured by densitometry and normalized against $\beta$-tubulin. Data are representative of at least three independent experiments. ${ }^{*} \mathrm{P}<0.01$ and ${ }^{* *} \mathrm{P}<0.01$ vs. control. GC, gastric cancer; 5-FU, 5-fluorouracil.

manner, demonstrating that the effects of caffeine on MGC-803 and SGC-7901 cells are consistent with previous studies. The protein expression levels of cell cycle-associated proteins were detected. The present results revealed that p21 levels were upregulated in MGC-803 cells, whereas cyclin D1 levels were downregulated in both GC cell lines, thus supporting the cell cycle-arresting effects of caffeine. The effects of caffeine on caspase- 9 and -3 were investigated, as these are key apoptosis-related factors in cancer cells. The results indicated that caffeine induces apoptosis via activation of the caspase-9/-3 pathway.

Notably, the effects of caffeine on cell growth inhibition and apoptosis in MGC-803 and SGC-7901 cells appeared to be sustained following caffeine withdrawal for a short period of time (0-16 h). A previous study indicated that caffeine mediates sustained growth inhibition of breast cancer-related myofibroblasts (20), and the present study provides additional evidence of the sustained effects of caffeine in cancer cells. Cell cycle progression is controlled by cyclin-CDK complexes, which include p21 CDK-interacting protein, kinase inhibitory proteins (KIP: p27 $7^{\mathrm{KIP} 1}$ and $\mathrm{p} 57^{\mathrm{KIP} 2}$ ), and CDK4 inhibitors (INK4: $\mathrm{p} 16^{\mathrm{INK} 4 \mathrm{a}}, \mathrm{p} 15^{\mathrm{INK} 4 \mathrm{~b}}, \mathrm{p} 18^{\mathrm{INK} 4 \mathrm{c}}, \mathrm{p} 19^{\mathrm{INK} 4 \mathrm{~d}}$ ). The $\mathrm{G}_{1}$ phase of the cell cycle is the only period during which cells may respond to extracellular cues, and progression depends on the balance between proliferative and antiproliferative signals. A few studies have demonstrated that caffeine affects cyclin D1 and INK4 expression and causes cell cycle arrest in cancer cells. In the present study, caffeine induced $\mathrm{G}_{0} / \mathrm{G}_{1}$ phase arrest in MGC-803 and SGC-7901 cells, which supported the apoptotic effects of this drug. Therefore, it was surmised that caffeine may induce sustained cell apoptosis in GC cells by mediating cyclin-CDK complexes. However, the mechanisms underlying the sustained effects of caffeine remain unknown. Further studies should investigate cell cycle arrest mechanisms in the sustained anticancer effects of caffeine and other drugs. Furthermore, key genes and pathways must be confirmed, and these may serve as novel targets in cancer prevention and chemotherapy.

In addition to its effects on the cell cycle, caffeine may exert sustained effects on gene and protein expression. The present study measured Bcl-2 and Cyt- $c$ expression to determine the relationship between the caspase-9/-3 pathway and the antiproliferative effects of caffeine. Caspase-9/-3 are downstream proteins of numerous molecular pathways. 

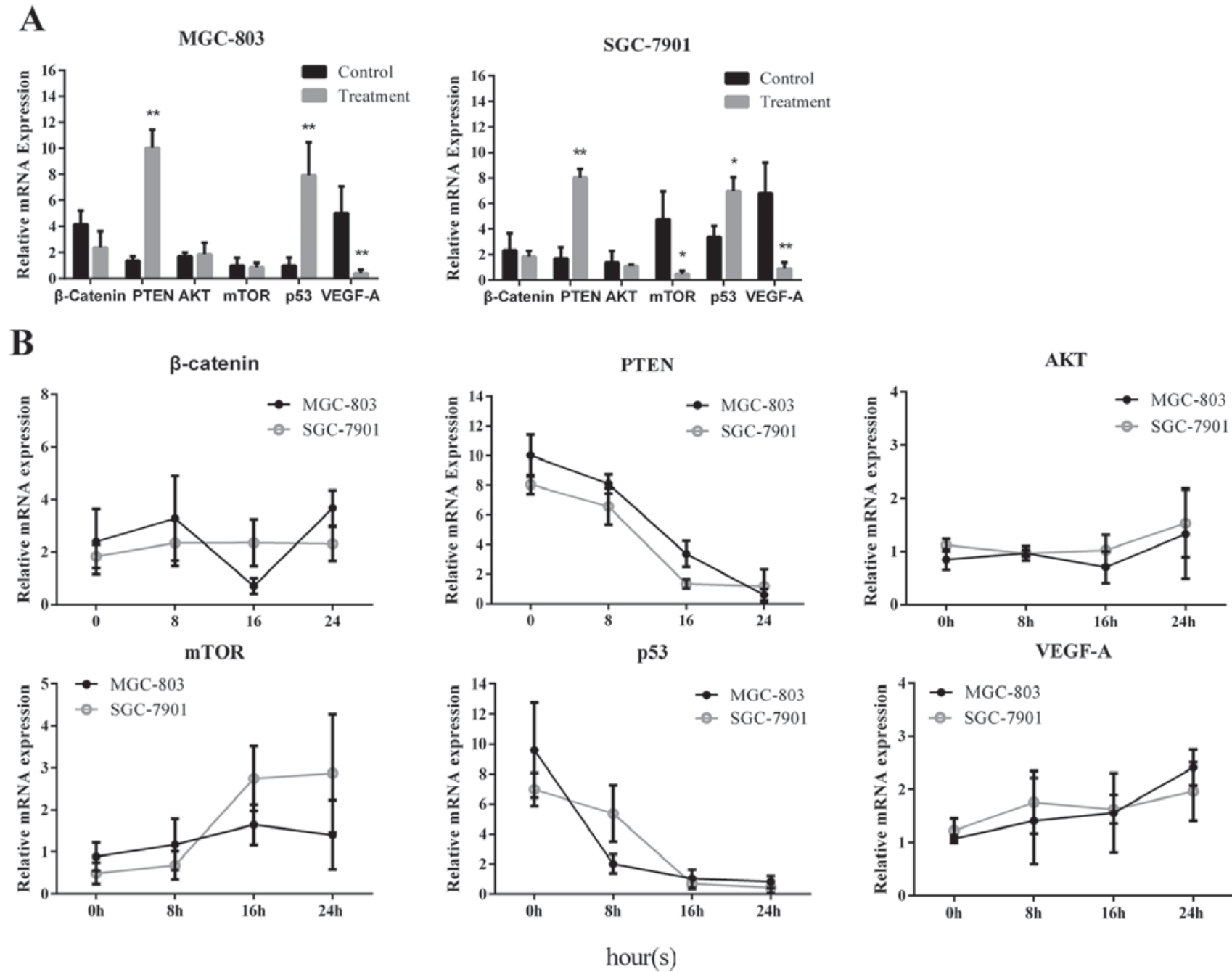

Figure 5. Expression of cancer-related factors was altered by caffeine treatment. MGC-803 and SGC-7901 cells were obtained via enzymatic digestion following caffeine treatment for $24 \mathrm{~h}$. Human gastric mucosa epithelial cells (GES-1) were used as an internal control. Relative mRNA expression levels were detected by reverse transcription-quantitative polymerase chain reaction, and the data were analysed using the $2^{-\Delta \mathrm{Cq}}$ method. (A) Relative mRNA expression levels of $\beta$-catenin, PTEN, AKT, mTOR, p53 and VEGF-A in MGC-803 and SGC-7901 cells were measured after $24 \mathrm{~h}$ of caffeine treatment. GES-1 cells were used the untreated normal control. (B) Relative mRNA expression levels of $\beta$-catenin, PTEN, AKT, mTOR, p53 and VEGF-A in MGC-803 and SGC-7901 cells were measured and recorded at the indicated time points after caffeine withdrawal. Data are representative of at least three independent experiments. ${ }^{*} \mathrm{P}<0.01$ and ${ }^{* *} \mathrm{P}<0.01$ vs. control. PTEN, phosphatase and tensin homolog; mTOR, mammalian target of rapamycin; VEGF-A, vascular endothelial growth factor-A; AKT, protein kinase B.

It was speculated that caffeine may induce sustained GC cell apoptosis via various upstream mediators, the results supported this hypothesis; caffeine treatment appeared to exert sustained effects on several cancer-related signalling pathways. Furthermore, it was revealed that the mRNA expression levels of PTEN and p53 were sensitive to caffeine treatment. During the early period $(8 \mathrm{~h})$ following caffeine withdrawal, the mRNA levels of these proteins remained relatively high, compared with those of the internal controls. Notably, psychotropic substances, including caffeine, may cause withdrawal symptoms, and these are considered a type of psychological syndrome (51). Similar effects were noted in the present study, which were attributed to changes in mRNA expression, as although the mRNA levels of PTEN were downregulated following caffeine withdrawal, these remained higher than value '1', thus suggesting that mRNA expression and translation was sustained (Fig. 5B). However, further studies are required to fully elucidate the effects of caffeine and explore the molecular mechanisms that are involved.

MicroRNAs (miRNAs), which are members of the non-coding RNA family, are widely regarded as key modulators of anticancer processes $(52,53)$. miRNAs also serve as downstream transcriptional targets of several genes in response to internal or external stimuli. Numerous studies have established that chemotherapeutic agents, such as 5-FU (54) and decitabine (55), can profoundly alter miRNA gene expression patterns. Notably, some non-chemotherapeutic drugs, such as caffeine and non-steroidal anti-inflammatory drugs, have been reported to alter miRNA gene expression $(56,57)$. miRNAs have been associated with sustained effects on cancer cells; mutant p53-273H promotes sustained epidermal growth factor (EGF)-induced extracellular signal-regulated kinase $1 / 2$ activation via the miR-27a/EGF receptor axis, 
thereby facilitating cell proliferation and tumourigenesis (58). As caffeine appears to alter miRNA expression, miRNAs may serve as effectors of the sustained anticancer effects of caffeine. Further research is required on this hypothesis; the potential association between caffeine and miRNA expression may be of therapeutic interest in the clinical management of cancer.

The anticancer effects of caffeine have been reported in various human cells and tissues, and similar results were noted in MGC-803 and SGC-7901 GC cells in the present study. Furthermore, caffeine was observed to induce GC cell apoptosis. The present study provided further experimental evidence for the effects of caffeine observed in several previous studies, however, the mechanisms underlying the sustained effects of caffeine on cancer cells require further investigation. Optimization of drug doses is a critical factor in balancing drug safety and efficacy. In the present study, 1-2 mM caffeine was effective in suppressing caspase-9 expression and inducing GC cell apoptosis in vitro. Although the efficacy of caffeine increased with increasing concentrations of the drug, doses $>2 \mathrm{mM}$ were toxic to normal gastric cells (data not shown). Previously, dose-escalation studies have been performed in order to establish potentially suitable oral administration doses for caffeine in clinical treatments or animal experiments $(59,60)$. The relationship between everyday caffeine intake and the risk of cancer is currently undefined $(61,62)$. Notably, there is potential for caffeine to be used in the adjuvant setting during chemotherapy application $(63,64)$. The differences in efficacy between oral or local delivery also need to be investigated. Furthermore, the mild analgesic effect of caffeine may be useful for post-operative recovery, however, further investigations into the potential clinical benefits of caffeine are required.

In conclusion, the present study investigated the role of caffeine in GC in targeting the apoptosis-related caspase-9/-3 pathway. These results may serve as supporting evidence for further studies regarding the anticancer effects of caffeine on gastrointestinal cancers.

\section{Acknowledgements}

The present study was supported by a research grant from the Jiangsu Province Department of Health (grant no. Z2010023).

\section{References}

1. Torre LA, Bray F, Siegel RL, Ferlay J, Lortet-Tieulent J and Jemal A: Global cancer statistics, 2012. CA Cancer J Clin 65: 87-108, 2015.

2. Danaei G, Vander Hoorn S, Lopez AD, Murray CJ and Ezzati M; Comparative Risk Assessment collaborating group (Cancers): Causes of cancer in the world: Comparative risk assessment of nine behavioural and environmental risk factors. Lancet 366 : 1784-1793, 2005

3. Olefson S and Moss SF: Obesity and related risk factors in gastric cardia adenocarcinoma. Gastric Cancer 18: 23-32, 2015.

4. Uemura N, Okamoto S, Yamamoto S, Matsumura N, Yamaguchi S, Yamakido M, Taniyama K, Sasaki N and Schlemper RJ: Helicobacter pylori infection and the development of gastric cancer. N Engl J Med 345: 784-789, 2001.

5. Shi J, Qu YP and Hou P: Pathogenetic mechanisms in gastric cancer. World J Gastroenterol 20: 13804-1319, 2014.

6. Kim B, Srivastava SK and Kim SH: Caspase-9 as a therapeutic target for treating cancer. Expert Opin Ther Targets 19: 113-127, 2015.
7. Goldstein A, Kaizer S and Warren R: Psychotropic effects of caffeine in man. II. Alertness, psychomotor coordination, and mood. J Pharmacol Exp Ther 150: 146-151, 1965.

8. Arnaud MJ: The pharmacology of caffeine. Prog Drug Res 31: 273-313, 1987.

9. Dunwiddie TV: Interactions between the effects of adenosine and calcium on synaptic responses in rat hippocampus in vitro. J Physiol 350: 545-559, 1984.

10. O'Keefe JH, Bhatti SK, Patil HR, DiNicolantonio JJ, Lucan SC and Lavie CJ: Effects of habitual coffee consumption on cardiometabolic disease, cardiovascular health, and all-cause mortality. J Am Coll Cardiol 62: 1043-1051, 2013.

11. Wilson DF: Effects of caffeine on neuromuscular transmission in the rat. Am J Physiol 225: 862-865, 1973.

12. Rousseau E, Ladine J, Liu QY and Meissner G: Activation of the $\mathrm{Ca}^{2+}$ release channel of skeletal muscle sarcoplasmic reticulum by caffeine and related compounds. Arch Biochem Biophys 267: 75-86, 1988.

13. Bessler H, Salman H, Bergman M and Djaldetti M: Caffeine alters cytokine secretion by PBMC induced by colon cancer cells. Cancer Invest 30: 87-91, 2012.

14. Bode AM and Dong Z: The enigmatic effects of caffeine in cell cycle and cancer. Cancer Lett 247: 26-39, 2007.

15. Conney AH, Zhou S, Lee MJ, Xie JG, Yang CS, Lou YR and Lu Y: Stimulatory effect of oral administration of tea, coffee or caffeine on UVB-induced apoptosis in the epidermis of SKH-1 mice. Toxicol Appl Pharmacol 224: 209-213, 2007.

16. Ku BM, Lee YK, Jeong JY, Ryu J, Choi J, Kim JS, Cho YW, Roh GS, Kim HJ, Cho GJ, et al: Caffeine inhibits cell proliferation and regulates PKA/GSK3beta pathways in U87MG human glioma cells. Mol Cells 31: 275-279, 2011

17. Miwa S, Sugimoto N, Shirai T, Hayashi K, Nishida H, Ohnari I, Takeuchi A, Yachie A and Tsuchiya H: Caffeine activates tumor suppressor PTEN in sarcoma cells. Int J Oncol 39: 465-472, 2011.

18. Hashimoto T, He Z, Ma WY, Schmid PC, Bode AM, Yang CS and Dong Z: Caffeine inhibits cell proliferation by G0/G1 phase arrest in JB6 cells. Cancer Res 64: 3344-3349, 2004.

19. Okano J, Nagahara T, Matsumoto K and Murawaki Y: Caffeine inhibits the proliferation of liver cancer cells and activates the MEK/ERK/EGFR signalling pathway. Basic Clin Pharmacol Toxicol 102: 543-551, 2008.

20. Al-Ansari MM and Aboussekhra A: Caffeine mediates sustained inactivation of breast cancer-associated myofibroblasts via up-regulation of tumor suppressor genes. PLoS One 9: e90907, 2014.

21. Rosendahl AH, Perks CM, Zeng L, Markkula A, Simonsson M, Rose C, Ingvar C, Holly JM and Jernström H: Caffeine and caffeic acid inhibit growth and modify estrogen receptor and insulin-like growth factor I receptor levels in human breast cancer. Clin Cancer Res 21: 1877-1887, 2015.

22. Liu JD, Song LJ, Yan DJ, Feng YY, Zang YG and Yang Y: Caffeine inhibits the growth of glioblastomas through activating the caspase-3 signaling pathway in vitro. Eur Rev Med Pharmacol Sci 19: 3080-3038, 2015.

23. Matsuoka S, Moriyama T, Ohara N, Tanimura K and Maruo T: Caffeine induces apoptosis of human umbilical vein endothelial cells through the caspase-9 pathway. Gynecol Endocrinol 22: 48-53, 2006.

24. Livak KJ and Schmittgen TD: Analysis of relative gene expression data using real-time quantitative PCR and the 2(-Delta Delta C(T)) method. Methods 25: 402-408, 2001.

25. Morgan ME and Vestal RE: Methylxanthine effects on caudate dopamine release as measured by in vivo electrochemistry. Life Sci 45: 2025-39, 1989.

26. Degubareff T and Sleator W Jr: Effects of caffeine on mammalian atrial muscle, and its interaction with adenosine and calcium. J Pharmacol Exp Ther 148: 202-214, 1965.

27. Solinas M, Ferré S, You ZB, Karcz-Kubicha M, Popoli P and Goldberg SR: Caffeine induces dopamine and glutamate release in the shell of the nucleus accumbens. J Neurosci 22: 6321-6324, 2002.

28. Daly JW, Bruns RF and Snyder SH: Adenosine receptors in the central nervous system: Relationship to the central actions of methylxanthines. Life Sci 28: 2083-2097, 1981.

29. Jarvis MJ: Does caffeine intake enhance absolute levels of cognitive performance? Psychopharmacology (Berl) 110: 45-52, 1993.

30. Corley J, Jia X, Kyle JA, Gow AJ, Brett CE, Starr JM, McNeill G and Deary IJ: Caffeine consumption and cognitive function at age 70: The Lothian Birth Cohort 1936 study. Psychosom Med 72: 206-214, 2010. 
31. Lindsay J, Laurin D, Verreault R, Hébert R, Helliwell B, Hill GB and McDowell I: Risk factors for Alzheimer's disease: A prospective analysis from the Canadian Study of Health and Aging. Am J Epidemiol 156: 445-453, 2002.

32. Shen ZX: Brain cholinesterases: II. The molecular and cellular basis of Alzheimer's disease. Med Hypotheses 63: 308-321, 2004

33. Ross GW, Abbott RD, Petrovitch H, Morens DM, Grandinetti A, Tung KH, Tanner CM, Masaki KH, Blanchette PL, Curb JD, et al: Association of coffee and caffeine intake with the risk of Parkinson disease. JAMA 283: 2674-2679, 2000.

34. Johnson-Kozlow M, Kritz-Silverstein D, Barrett-Connor E and Morton D: Coffee consumption and cognitive function among older adults. Am J Epidemiol 156: 842-850, 2002.

35. Ferreira DD, Stutz B, de Mello FG, Reis RA and Kubrusly RC: Caffeine potentiates the release of GABA mediated by NMDA receptor activation: Involvement of A1 adenosine receptors. Neuroscience 281: 208-215, 2014.

36. Hursel R and Westerterp-Plantenga MS: Catechin- and caffeine-rich teas for control of body weight in humans. Am J Clin Nutr 98 (6 Suppl): S1682-S1693, 2013.

37. van Dam RM and Feskens EJ: Coffee consumption and risk of type 2 diabetes mellitus. Lancet 360: 1477-1478, 2002.

38. Tuomilehto J, Hu G, Bidel S, Lindström J and Jousilahti P. Coffee consumption and risk of type 2 diabetes mellitus among middle-aged Finnish men and women. JAMA 291: 1213-1219, 2004.

39. Salazar-Martinez E, Willett WC, Ascherio A, Manson JE, Leitzmann MF, Stampfer MJ and Hu FB: Coffee consumption and risk for type 2 diabetes mellitus. Ann Intern Med 140: 1-8, 2004.

40. Sartorelli DS, Fagherazzi G, Balkau B, Touillaud MS Boutron-Ruault MC, de Lauzon-Guillain B and Clavel-Chapelon F: Differential effects of coffee on the risk of type 2 diabetes according to meal consumption in a French cohort of women: The E3N/EPIC cohort study. Am J Clin Nutr 91: 1002-1012, 2010.

41. Carlsson S, Hammar N, Grill V and Kaprio J: Coffee consumption and risk of type 2 diabetes in Finnish twins. Int J Epidemiol 33 616-617, 2004

42. Hamer M, Witte DR, Mosdøl A, Marmot MG and Brunner EJ: Prospective study of coffee and tea consumption in relation to risk of type 2 diabetes mellitus among men and women: The Whitehall II study. Br J Nutr 100: 1046-1053, 2008.

43. Akash MS, Rehman K and Chen S: Effects of coffee on type 2 diabetes mellitus. Nutrition 30: 755-763, 2014.

44. Cheng YC, Ding YM, Hueng DY, Chen JY and Chen Y: Caffeine suppresses the progression of human glioblastoma via cathepsin $B$ and MAPK signaling pathway. J Nutr Biochem 33: 63-72, 2016.

45. Hashibe M, Galeone C, Buys SS, Gren L, Boffetta P, Zhang ZF and La Vecchia C: Coffee, tea, caffeine intake, and the risk of cancer in the PLCO cohort. Br J Cancer 113: 809-816, 2015.

46. Wu S, Han J, Song F, Cho E, Gao X, Hunter DJ and Qureshi AA: Caffeine intake, coffee consumption and risk of cutaneous malignant melanoma. Epidemiology 26: 898-908, 2015.

47. Dubrez L, Coll JL, Hurbin A, Solary E and Favrot MC: Caffeine sensitizes human H358 cell line to p53-mediated apoptosis by inducing mitochondrial translocation and conformational change of BAX protein. J Biol Chem 276: 38980-38987, 2001.

48. Jafari M and Rabbani A: Dose and time dependent effects of caffeine on superoxide release, cell survival and DNA fragmentation of alveolar macrophages from rat lung. Toxicology 149: $101-108,2000$

49. Fernandez MJ, López A and Santa-Maria A: Apoptosis induced by different doses of caffeine on Chinese hamster ovary cells. J Appl Toxicol 23: 221-224, 2003.
50. Ito K, Nakazato T, Miyakawa Y, Yamato K, Ikeda Y and Kizaki M: Caffeine induces G2/M arrest and apoptosis via a novel p53-dependent pathway in NB4 promyelocytic leukemia cells. J Cell Physiol 196: 276-283, 2003.

51. Juliano LM, Huntley ED, Harrell PT and Westerman AT: Development of the caffeine withdrawal symptom questionnaire: Caffeine withdrawal symptoms cluster into 7 factors. Drug Alcohol Depend 124: 229-234, 2012.

52. Gong Y, Ren J, Liu K and Tang LM: Tumor suppressor role of miR-133a in gastric cancer by repressing IGF1R. World J Gastroenterol 21: 2949-2958, 2015.

53. Ren J, Huang HJ, Gong Y, Yue S, Tang LM and Cheng SY: MicroRNA-206 suppresses gastric cancer cell growth and metastasis. Cell Biosci 4: 26, 2014.

54. Rossi L, Bonmassar E and Faraoni I: Modification of miR gene expression pattern in human colon cancer cells following exposure to 5-fluorouracil in vitro. Pharmacol Res 56: 248-253, 2007.

55. Garzon R, Pichiorri F, Palumbo T, Visentini M, Aqeilan R, Cimmino A, Wang H, Sun H, Volinia S, Alder H, et al: MicroRNA gene expression during retinoic acid-induced differentiation of human acute promyelocytic leukemia. Oncogene 26: 4148-4157, 2007.

56. Yiannakopoulou E: Targeting epigenetic mechanisms and microRNAs by aspirin and other non steroidal anti-inflammatory agents-implications for cancer treatment and chemoprevention. Cell Oncol (Dordr) 37: 167-178, 2014.

57. Varma SD and Kovtun S: Protective effect of caffeine against high sugar-induced transcription of microRNAs and consequent gene silencing: A study using lenses of galactosemic mice. Mol Vis 19: 493-500, 2013.

58. Wang W, Cheng B, Miao L, Mei Y and Wu M: Mutant p53-R273H gains new function in sustained activation of EGFR signaling via suppressing miR-27a expression. Cell Death Dis 4: e574, 2013.

59. Altman RD, Lang AE and Postuma RB: Caffeine in Parkinson's disease: A pilot open-label, dose-escalation study. Mov Disord 26: 2427-2431, 2011

60. Lee IA, Low D, Kamba A, Llado V and Mizoguchi E: Oral caffeine administration ameliorates acute colitis by suppressing chitinase 3-like 1 expression in intestinal epithelial cells. J Gastroenterol 49: 1206-1216, 2014.

61. Guercio BJ, Sato K, Niedzwiecki D, Ye X, Saltz LB, Mayer RJ, Mowat RB, Whittom R, Hantel A, Benson A, et al: Coffee intake, recurrence and mortality in stage III colon cancer: Results from CALGB 89803 (Alliance). J Clin Oncol 33: 3598-3607, 2015.

62. Sanikini H, Dik VK, Siersema PD, Bhoo-Pathy N, Uiterwaal CS, Peeters PH, González CA, Zamora-Ros R, Overvad K, Tjønneland A, et al: Total, caffeinated and decaffeinated coffee and tea intake and gastric cancer risk: Results from the EPIC cohort study. Int J Cancer 136: E720-E730, 2015.

63. Hayashi M, Tsuchiya H, Yamamoto N, Karita M, Shirai T, Nishida H, Takeuchi A and Tomita K: Caffeine-potentiated chemotherapy for metastatic carcinoma and lymphoma of bone and soft tissue. Anticancer Res 25: 2399-2405, 2005.

64. Miwa S, Kitamura S, Shirai T, Hayashi K, Nishida H, Takeuchi A, Nojima T and Tsuchiya H: Desmoplastic small round cell tumour successfully treated with caffeine-assisted chemotherapy: A case report and review of the literature. Anticancer Res 30: 3769-3774, 2010. 